\title{
A Double-chained Polyrotaxane: Cucurbituril 'Beads' Threaded onto a Double-chained One-dimensional Coordination Polymer ${ }^{\dagger}$
}

\author{
Ki-Min Park, ${ }^{\ddagger}$ Eunsung Lee, Soo-Gyun Roh, Jaheon Kim, ${ }^{\S}$ and Kimoon Kim ${ }^{\star}$ \\ National Creative Research Initiative Center for Smart Supramolecules, and Department of Chemistry Division of holecular \\ and Life Sciences. Pohang Unwersiti of Science and Technologv. San 31 Hvojadong, Pohang 790-784, Korea
}

Received Mav 18, 2004

Key Words : Polỵrotaxanes. Self-assembly. Metal ions. Cucurbituril

The synthesis of interlocked molecules ${ }^{1}$ such as rotaxanes and catenanes has attracted considerable interests in recent years because of their potential applications as well as their aesthetic appeal. Some years ago. we developed a new synthetic methodology to construct polyrotaxanes using the principles of self-assembly and coordination chemistry, and successfully synthesized one-, two- and three-dimensional (ID, 2D and 3D) polyrotaxanes with high structural regularities in the solid state. ${ }^{\hat{2} .3}$ Extending this approach we also synthesized molecular necklaces (MN) in which a number of small rings are threaded on a large ring. ${ }^{4}$ Four and five-membered molecular necklaces ([4]MN and [5]MN. respectively) have been synthesized in a near quantitative yield without laborious purification." Using a " $2+2$ " approach, ${ }^{\text {sb }}$ we also synthesized a five-membered molecular necklace $([5] \mathrm{MN})$ from the reaction of a preorganized Lshaped pseudorotaxane and transition metal ions. However, the reaction of the L-shaped pseudorotaxane and metal ions also produced other novel supramolecular species such as "square-wvave-shaped" ID polyrotaxanes. ${ }^{\text {If }}$ Herein we report another new type of supramolecular species. a doublechained one-dimensional (ID) polyrotaxane synthesized from the reaction of the L-shaped pseudorotaxane and metal ions (Scheme 1).

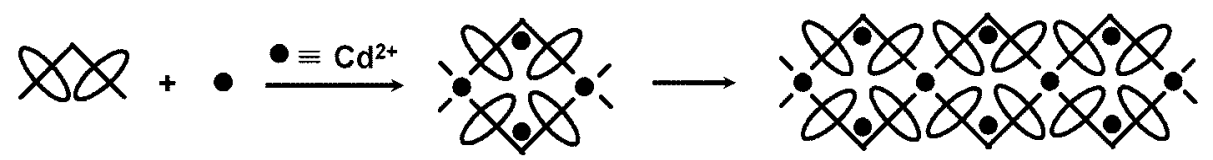

Scheme 1. Schematic illustration for synthesis of a double-chained one-dimensional polyrotaxane 3.
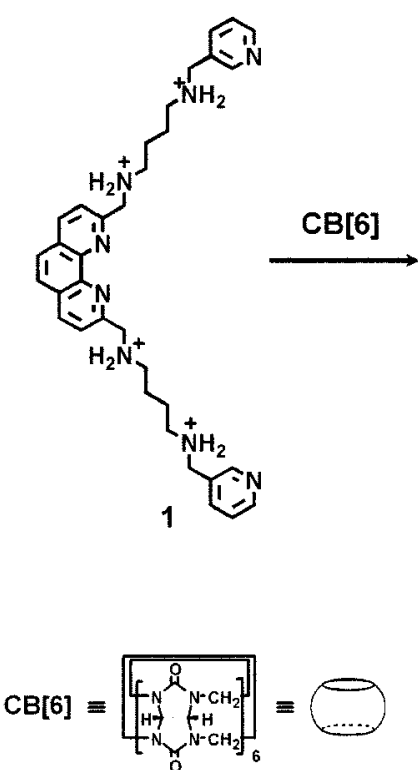

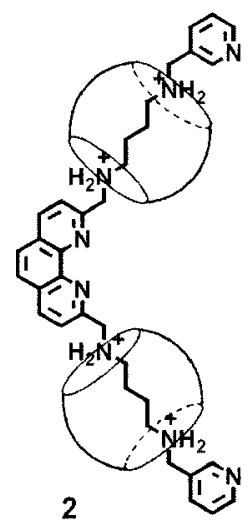
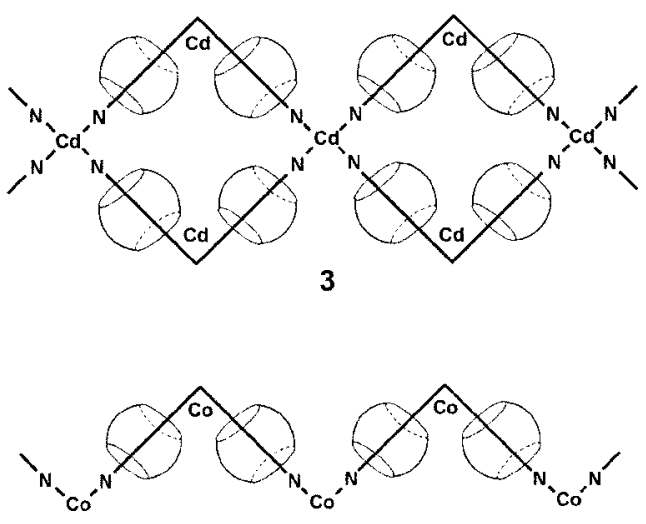

$\|$

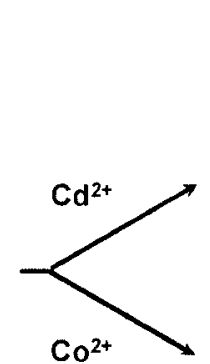

3

4

Scheme 2. Synthesis of the double-chained one-dimensional polyrotaxane 3 and the zigzag-shaped one-dimensional polyrotaxane 4.

Dedicated to Professor Yong Hae Kin for his outstanding achievement in organic chemistry.

${ }^{*}$ Corresponding Author. Phone: -82-54-279-2113: Fax: +82-54-279-8129: e-mail: kkim apostech.ac.ki

Present address: "Department of Chemistry and Research Institute of Natural Sciences. Gyeongsang National University. Chitiju 660-701. Korea. Department of Chemistry. Soongsil University. 1-1 Sangdo-5dong. Dongakku. Seoul 156-743. Korea. 
(a)

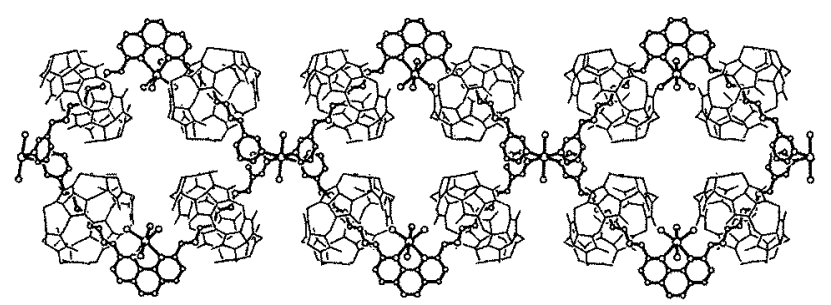

(b)

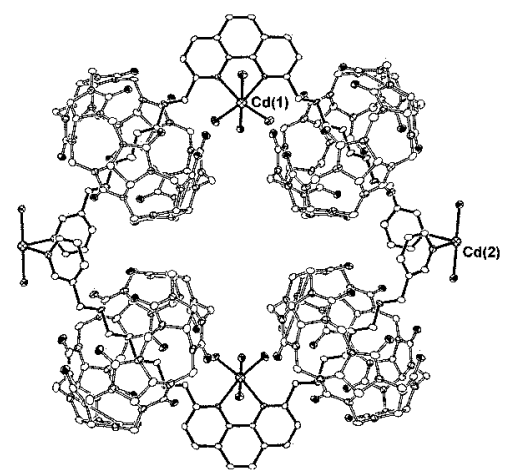

Figure 1. (a) A crystal structure of 3 showing a double-chained 1D polyrotaxane. (b) A five-membered molecular necklace ([5]MN) behaves as a basic building block of 3 .

The synthesis involves initial formation of the psendorotaxane 2 by threading two cucurbituril $(\mathrm{CB}[6]))^{6}$ "beads' onto the 'L-shaped string' 1 containing two pyridyl groups at the terminals for metal coordination. Formation of the double-chained polyrotaxane 3 is achieved in the form of colorless crystals when $\mathrm{Cd}\left(\mathrm{NO}_{3}\right)_{2} \cdot 6 \mathrm{H}_{2} \mathrm{O}$ is allowed to react with 2 in water at room temperature for two weeks (Scheme 2). The X-ray crystal structure of 3 reveals a double-chained $\mathrm{ID}$ polyrotaxane in which $\mathrm{CB}[6]$ beads are threaded onto a ID double-chained coordination polymer network (Figure la). The asymmetric unit of 3 consists of two different cadmium ions, $\mathrm{Cd}(1)$ and $\mathrm{Cd}(2)$, one pseudorotaxane (2) moiety. and five coordinated water molecules. $\mathrm{Cd}(1)$ is coordinated by two nitrogen atoms of the phenanthroline unit and four water molecules in a distorted octahedral geometry. $\mathrm{Cd}(1)$ is displaced by approximately $0.87 \AA$ from the mean plane of the phenanthroline unit to avoid repulsion from the side arms of threaded $\mathrm{CB}[6]$ s leading to a distorted octahedral geometry. Hydrogen bonding interactions exist between the water molecules bound to the cadmium ion and the oxygen atoms of $\mathrm{CB}[6]$ with a distance ranging from $2.76 \AA$ to $2.96 \AA$ $\mathrm{Cd}(2)$ is situated at an inversion center with coordination from two nitrogen atoms of two pyridyl units of $\mathbf{2}$ and one water molecule in the asymmetric unit. Thus, the metal ion is bonded to four pyridine nitrogen atoms occupying the equatorial positions. and to two water oxygen atoms occupying the axial positions.

A close examination of the structure reveals that a tetragonal, five-membered molecular necklace [5]MN composed of four cadmium ions and two pseudorotaxanes constitutes a basic building block of the ID polyrotaxane (Figure lb). The comers of the supramolecular tetragon are occupied by two types of cadmium ions, viz., $\mathrm{Cd}(\mathrm{l})$ and $\mathrm{Cd}(2)$ both of which show octahedral coordination. The basic building block, [5]MN, is better described as a rectangular unit with dimensions of about $17.61 \times 17.57 \AA$ corresponding to the distances from the center ring of the phenanthroline to the cadmium ions. The double-chained ID polyrotaxane (3) is formed by the comnection of [5]MN through the cadmium ions and runs along the $\left[\begin{array}{lll}1 & 0 & 1\end{array}\right]$ direction. The double-chained ID polyrotaxane also forms $\pi-\pi$ stacking with each other with a mean separation of $3.37 \AA$ between one phenanthroline unit and adjacent phenanthroline unit.

In this approach, however. the metal ion plays an important role in forming the ultimate structure at least in the solid state. Under similar conditions. nitrate salts of other transition metal ions such as $\mathrm{Co}^{\hat{i}^{-}}, \mathrm{Ni}^{\hat{i}^{+}}$. $\mathrm{Zn}^{\hat{i}^{-}}$and $\mathrm{Ag}^{+}$do not yield a double-chained ID polyrotaxane. Instead, they afford simple ID polyrotaxanes. For example. the reaction of $\mathbf{2}$ and $\mathrm{CO}^{2+}$ in aqueous phase yields a zigzag-typed ID-polyrotaxane (t) as confirmed by X-ray crystallograply (Figure 2). As shown in Scheme 2, the cis coordination of two pyridyl units of 2 to the metal center makes the polymer chain a zigzag shape. In the crystal, the coordination polymer chain runs along the $a$ axis and forms $\pi-\pi$ stacking between adjacent phenanthroline units, but the efficiency of $\pi-\pi$ stacking looks weaker than that of the double-chained ID polyrotaxane ( 3 ).

In summary. we present an efficient synthesis of a doublechained ID polyrotaxane built with a molecular necklace [5]MN as a basic building block using a preorganized Lshaped pseudorotaxane and a metal ion. Here. as well as in our earlier work. we demonstrate that such topologically intriguing supramolecular species can be readily assembled from carefully designed organic building blocks and properly chosen metal ions or complexes.

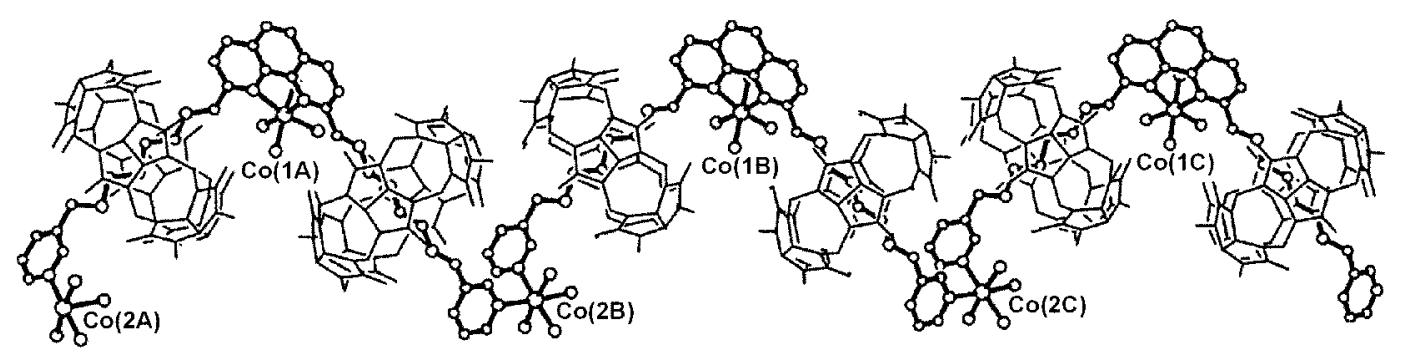

Figure 2. A crystal structure of the zigzag-shaped one-dimensional polyrotaxane 4 


\section{Experimental Section}

3. A $0.003 \mathrm{M}$ solution of pseudorotaxane 2 in $\mathrm{H}_{2} \mathrm{O}$ was layered over a $0.3 \mathrm{M}$ solution of $\mathrm{Cd}\left(\mathrm{NO}_{3}\right)_{2}$ in $\mathrm{H}_{2} \mathrm{O}$ in a diffision tube to produce colorless, plate-shape, X-ray quality crystals (3) in 2 weeks (27 $\mathrm{mg}, 14 \%$ ). Elemental analysis calcd for $\mathrm{C}_{21} \mathrm{H}_{236} \mathrm{~N}_{136} \mathrm{O}_{96} \mathrm{Cd}_{3}+47 \mathrm{H}_{2} \mathrm{O}: \mathrm{C} 35.49 . \mathrm{H}$ 4.63. N 24.60: found: C 35.46. H 4.68. N 24.52.

4. Pale purple, plate-shape. X-ray quality crystals of 4 were prepared by the same procedure as that for 3 except that $\mathrm{Co}\left(\mathrm{NO}_{3}\right)_{2}$ instead of $\mathrm{Cd}\left(\mathrm{NO}_{3}\right)_{2}$ was used (36 mg. 37\%). Elemental analysis calcd for $\mathrm{C}_{1106} \mathrm{H}_{118} \mathrm{~N}_{64} \mathrm{O}_{48} \mathrm{CO}_{2} 25 \mathrm{H}_{2} \mathrm{O}: \mathrm{C}$ 35.12, H 4.67, N 24.73: found: C 35.03, H 4.56. N 24.78 .

Crystal data for 3: $\mathrm{C}_{166} \mathrm{H}_{310} \mathrm{~N}_{6 j} \mathrm{O}_{50} \mathrm{Cd}_{1.5,}, M_{\mathrm{r}}=3955.94$. triclinic. space group $P(-1)$ (No. 2). $a=14.3457(3) \AA, b=$ $23.8120(7)$ A. $c=24.5626(4)$ A. $\alpha=82.3422(4)^{\circ} . \beta=$ $77.1756(10)^{\circ}, \gamma=83.1308(9)^{\circ} . U=8073.0(6) \AA^{3}, T=188 \mathrm{~K}$. $Z=2, \mu\left(\mathrm{Mo}_{-1}\right)=0.328 \mathrm{~mm}^{-1}: 2302$ unique reflections measured: $R 1(I>2 \sigma(I))=0.0995, w R 2$ (all data) $=0.2664$. $\mathrm{GOF}=1.156$. For $4: \mathrm{C}_{160} \mathrm{H}_{154} \mathrm{~N}_{64} \mathrm{O}_{56} \mathrm{Co}_{2} . M_{\mathrm{r}}=3849.03$. monoclinic. space group $P 2{ }_{1} / c$ (No. 14). $a=23.4338(2) A . b$ $=14.7211(3) \AA . c=44.7781(8) \AA, \beta=90.8740(10)^{\circ}, U=$ $15445.4(4) \AA^{3}, T=188 \mathrm{~K} . Z=4, \mu\left(\mathrm{Mo}-\mathrm{K}_{t x}\right)=0.347 \mathrm{mum}^{-1}$. 2415 unique reflections measured: $R I(I>2 \sigma(I))=0.0973$. $w R 2$ (all data) $=0.2777, \mathrm{GOF}=1.061$. The intensity data were collected with a Sientens SMART CCD diffractometer using monochromated Mo $\mathrm{K}_{a x}$ radiation $\left(\lambda\left(\mathrm{K}_{a(x)}\right)=0.71073\right.$ A). The structures were solved by the Patterson method (SHELXS-86) and refined by full-matrix least-squares method (SHELXL-93). All nonlydrogen atoms were refuned anisotropically. Crystallographic Data for the structures reported in this paper have been deposited with the Cambridge Crystallographic Data Centre as supplementary publications no. CCDC-167554 (3) and CCDC-168282 (4). Copies of the data can be obtained free of charge on application to CCDC, 12 Union Road. Cambridge CB2 IEZ. UK (fax: (+44) 1223-336-033: e-ntail: deposita ccdc.cant. ac.uk).
Acknowledgment. We gratefully acknowledge the Creative Research Initiative Program of the Korean Ministry of Science and Teclunology for support of this work and Professor P. K. Bharadwaj for reading the manuscript.

\section{References and Notes}

1. Recent review articles: (a) Philp. D.: Stoddart. J. F. Angew! Chem. Int. Ed. 1996. 35. 1154. (b) Holecular Catenanes, Rotaxanes and Knots: Sauvage. T.-P.: Dietrich-Buchecker. C. O.. Eds.: VCHWiley: Weinheim. 1999. (c) Kinn. K. Chent. Soc. Rev. 2002. 31. 96

2. (a) Whang, D.: Jeon, Y.-M.: Heo, J.: Kim, K. J. Am. Chem Soc 1996. 118,11333 (b) Whang. D; Kim. K. J. Am. Chem. Soc 1997. 119. 451. (c) Whang. D.: Heo. T.: Kiml. C.-A.: Kim. K. $J$. Chent Soc. Chent Conmum. 1997. 2361. (d) Lee. E.: Heo. T.: Kim. K. Angew. Chem. Int Ed 2000. 39. 2699. (e) Park. K.-M.: Whang. D.: Lee, E; Heo, J.: Kim. K. Chent. Eur. J. 2002, 8. 498 (f) Park. K.-M.: Roh, S.-G.; Lee, E.: Kim, J.: Kim, H.-J.; Lee. J. W. Kim. K. Supramol. Chem. 2002, 14. 153 .

3. (Pseudo)rotaxanes containing CB[6]: (a) Jur1. S. I.: Lee. J. W: Sakamoto. S: Yamaguchi. K.: Kim. K. Tetrahedron Lett. $\mathbf{2 0 0 0}$. H. 471. (b) Lee. J. W.: Kim. K. Chen. Commm. 2001. 1042. (c) Lee. J. W: Choi. S. W. Ko, Y. H. Kim. S.-Y; Kim. K. Bull. Koman Chem. Soc, 2002, 23. 1347. (d) Mock. W. L.: Pierpont, J. J. Chem. Soc. Chem. Commu $1990.15(19$

4. A molecular necklace consisting of $(n-1)$ rings threaded on a large ring (total $n$ rings) is denoted as [ $n] \mathrm{MN}$. which is a topological stereoisomer of classical [n]catenane where $n$ rings are mechanically interlocked with each other in a linear fashion (see the reference $1 \mathrm{c}$ )

5. (a) Whang, D.: Park. K.-M.; Heo. J.: Kim. K. J. Am. Chem. Soc. 1998. 120. 4899. (b) Roh. S.-G.: Park. K.-M.: Park. G.-T.: Sakamoto. S: Yamaguchi. K.: Kim. K. Angew: Chem., hnt. Ed. 1999. 38. 638. (c) Park. K.-M.: Kim. S.-Y.: Heo. T.: Whang. D.: Sakamoto. S.; Yamaquehi. K.; Kim, K. J. Am. Chent Soc. 2002, 124. 2140. (d) Ko. Y. H.: Kim. K.: Kang. J.-K: Chun, H; Lee, J. W.; Sakamoto. S.; Yamaguchi. K.: Fettinger, J. C.; Kim. K. J. Am. Chem. Soc. 2004. 126. 1932.

6. Reviews on cucurbiturils (a) Mock. W. L. In Conprehensine Supranolecular Chemistry Vögtle. F.. Ed.: Pergamon: Oxford. 1996: Vol. 2, pp 477-493. (b) Lee, J. W.: Samal, S. Selvapalam. N.: Kim. H.-J.; Kim, K. Acc. Chem. Res. 2003, 36. 621. 